\title{
Never Stop Learning
}

Dr Dashrath Kafle Chief Editor

"Once you stop learning you start dying "

\section{Albert Einstein}

Somebody said" Just graduated I always felt that I know everything. As I slowly spent time in profession, I felt like I knew nothing. After so many years of practice I now feel that I am learning something." Probably we do not deny with this statement either. Knowledge is like an ocean. The recipient is like a vessel. We can receive knowledge of ocean in a cup or bucket or in a big tanker. But we can never over empty the ocean. Orthodontics is a vast subject which not only include regular medical subjects but also extensive study of mechanics, appliance design , force and vectors as well. It truly demands some knowledge of physics and chemistry apart from biology. The more we are knowledgeable the better service and education we can cater to our patients and students respectively. Learning is a never ending process. Every day/week/year we learn new things as well as we relearn the already known facts. This is called updating ourselves in profession. There are number of ways to update in our profession like Continuing Dental Education(CDE), study clubs, participation and presentations in societies' meetings and conferences, publications, online webinars and text books to name few. Collectively we call it Continuing Professional Development (CPD).

Recetly there are numbers of concern about the need and compulsion of CPD points. CPD is not the compulsion, it is the need for every professionals. CPD is the way of keeping us updated in our profession. We know how important the professional update is. However in a developing countries, it should be easily accessible and affordable. It should never be means of earning for certain group of people in the name of professional development courses. Education must not be always expensive. This is the responsibility of a Nation towards her skilled manpower and professional societies towards their members. Orthodontic and Dentofacial Orthopedic Association of Nepal(ODOAN) is the professional organization of registered orthodontists established to uplift the quality of orthodontic service and education in Nepal. Knowing all the aforementioned difficulties, ODOAN is doing commendable job by trying to help its members through various means. To cut off the CDE cost, ODOAN has started conducting programs at the academic institutes. This has two major impacts, first: knowledge is shared in the academic environment, among the students of different level as well as faculties and other interdisciplinary colleagues rather than in an expensive hotels; second: the significant amount of economic burden is reduced for the participants. So moving CPDs from hotels to colleges should be the drive in the coming days too. This is going to attract more students and colleagues and create safe learning environment in the premises of academic institutes. Whatever the means we should not stop learning in our profession. Education will keep our profession alive.

Note: From this year onwards, biannual issues of OJN will be published in January-June and July-December format. 